División del trabajo en familias de dos proveedores.

Relato desde ambos géneros y dos generaciones*

\title{
Catalina Wainerman**
}

En el contexto de las fuertes transformaciones sociales acaecidas desde la instalación de la crisis en los ochenta en la Argentina, el modelo tradicional del "único proveedor (varón)" disminuyó y el de "dos proveedores" aumentó. En el Área Metropolitana de Buenos Aires las cifras respectivas son de $-23 \%$ y $+68 \%$ entre 1980 y 1994. La transformación pone en cuestión los valores establecidos acerca de la división del trabajo por género en la sociedad.

La investigación que reseña el artículo procuró responder en qué medida la Argentina está asistiendo a una "revolución estancada" a la Hochschild, o al advenimiento de "nuevas familias" a la Goldscheider y Waite. En entrevistas separadas con ambos miembros de 35 parejas conyugales de familias de dobles proveedores de sectores medios, residentes en Buenos Aires, se indagó la división del trabajo entre ambos en comparación con la prevaleciente en sus hogares de origen, además de sus imágenes y representaciones acerca del género, la paternidad y la maternidad, y la pareja conyugal. Los resultados muestran que la división del trabajo se alejó del modelo tradicional de roles segregados para seguir más uno transicional que uno igualitario. El cambio intergeneracional no fue parejo: la paternidad ganó muchos más adeptos que la domesticidad. Es decir, los varones incrementaron su participacion en el cuidado de los niños mucho más que en la atención de la casa, que sigue definida como femenina. Las mujeres no disminuyeron su elevada participación en la domesticidad y la maternidad, además invadieron actividades del hogar tradicionalmente masculinas.

\section{Introducción}

A partir de los años cincuenta y durante tres décadas, la Argentina, como el resto de América Latina, fue testigo de ún crecimiento sostenido de su economía con sólo algunas fluctuaciones. Entrando en los ochenta, esa dinámica disminuyó de manera drástica para llevar a la Argentina a vivir la crisis económica más profunda desde la de 1930. La política económica que puso en práctica el proceso militar a partir de marzo de 1976, persiguió la eficiencia y la modernización de la estructura productiva. Paradójicamente, al hacerlo, trajo aparejado un endeudamiento externo sin precedentes, disminución del ritmo de

* Ponencia presentada en el congreso de la Latin American Studies Association, The Palmer House Hilton Hotel, Chicago, septiembre 24-26, 1998.

** Consejo Nacional de Investigaciones Científicas y Técnicas (Conicet) / Centro de Estudios de Población (Cenep), Buenos Aires, Argentina. Correo electrónico: catalina@cenep.satlink.net 
crecimiento del empleo y de los salarios reales, incremento de los precios y de la inflación, desindustrialización y terciarizacion de la producción y el empleo, crecimiento significativo de la desocupación, de la subutilización de recursos y de la informalidad y la pobreza. El efecto fue diverso para las mujeres y para los varones.

Desde la segunda posguerra, hasta los sesenta y más aceleradamente después de los setenta, las mujeres habían aumentado su participación en la fuerza de trabajo. Este movimiento de la casa al trabajo iba contra la corriente de una fuerza de trabajo global decreciente, ya que los jóvenes, que prolongaron su escolaridad, retrasaron su ingreso al mundo del trabajo mientras los mayores adelantaron su salida en pos de la conquistada jubilación y el retiro. A estos grupos se les añadieron, desde mediados de los setenta y aún más desde los ochenta, los varones jefes de hogar que redujeron su participación laboral por efecto de la crisis.

Las mujeres que entraron en mayor número al mercado de trabajo entre 1970 y 1980 tenían entre 25 y 55 años dé edad, su participación en todo el país creció de 29 a $33 \%$. Entre ellas, las de 35 a 44 años crecieron aún más, de 28 a $34 \%$. Se trata fundamentalmente de mujeres casadas y unidas, en su mayoría cónyuges del jefe del hogar y relativamente más educadas, de los sectores medios y altos de la sociedad. Aparece así una tendencia a una participación más estable a lo largo del curso de la vida, semejante a la de las mujeres de los países desarrollados. Entretanto, los varones disminuían su participación desde el $89 \%$ que habían alcanzado en los cincuenta, a 85,80 y $75 \%$ adonde cayeron en 1960, 1970 y.1980, respectivamente.

La expansión de la educación, y la equiparación con los varones, impulsó el incremento de la oferta laboral de las mujeres. La postergación del matrimonio y la reducción del tamaño de la familia hicieron lo suyo en igual sentido.

La creciente participación económica de las mujeres en la década de los ochenta no se puede interpretar simple y llanamente como señal de modernización, desarrollo o crecimiento, como se entendía en los setenta. Entonces, las esperanzas del cambio de la condición de las mujeres se cifraban en su incorporación al mercado de trabajo. Ahora, en un país empobrecido, con un Estado achicado que proveía menos servicios sociales, las mujeres salieron a reemplazar los salarios deteriorados de los cónyuges, y/o a mantener el nivel de consumo familiar. Lo que buscaban era frenar la caída cuesta abajo. Estos movimientos acentuaron la "feminización" de la fuerza de trabajo. 
En muchas zonas del país, las mujeres que salieron a trabajar terminaron engrosando las filas de un ejército de desocupados y subocupados, en una economía incapaz de crear suficientes puestos de trabajo. Así, las mujeres pagaron el costo del ajuste. Y lo han hecho en un mercado de trabajo estragado por la desocupación, la precarización, la flexibilización y la explotación al que, por otra parte, un creciente ejército de excluidos y excluidas pugna por entrar.

Entre 1980 y 1997, en el Área Metropolitana de Buenos Aires, igual que en otras zonas del país, la tasa de actividad de las mujeres de 15 a 64 años de edad, creció de 38 a 53\%. Como la de los varones se mantuvo en $85 \%$, se acentuó el proceso de feminización ya iniciado en las décadas anteriores. Igual que entonces, en esta década las mujeres que más mano de obra aportaron fueron las de edad media y alta (30 a 60 años), que crecieron casi $50 \%$, y las cónyuges, casi $66 \%$. Las que encontraron empleo, lo hicieron en el sector terciario, prestando servicios. La desindustrialización alcanzó mayor envergadura entre las mujeres que entre los varones. Mientras esto ocurría, se acortaban las diferencias entre ellas y ellos en el campo del desempleo que durante décadas había afectado más a las mujeres. En los años ochenta se precipitó el desempleo masculino, sobre todo entre los jefes de hogar.

La salida a trabajar de las mujeres casadas, con cargas de familia, ha significado un cambio revolucionario. De una fuerza de trabajo formada predominantemente por hijas trabajadoras (como fue hasta los años sesenta) viramos a otra formada por hijas y madres trabajadoras. Efectivamente, hasta los sesenta, la mayoría de las mujeres que salían a trabajar lo hacían en su juventud, antes de casarse o de tener su primer hijo. Luego dejaban de trabajar para dedicarse a la casa y los hïjos, porque se entendía que era parte de la hombría de bien de los maridos ser el sustento de su familia. Los varones, en cambio, no tenían elección. Ingresaban al mercado de trabajo y allí se quedaban, ocupados o buscando trabajo, hasta su retiro o su muerte. Casarse, tener hijos, pocos o muchos, que el menor ingresara a la escuela, no afectaba su relación estable con el mercado de trabajo. Para ellas, en cambio, las entradas y salidas del mercado de trabajo estaban íntimamente ligadas a esos cambios vitales.

Actualmente las mujeres entran y permanecen en el mercado de trabajo -sea como ocupadas o buscando trabajo-, igual que los varones, cualquiera sea su situación familiar. Lo mismo da que formen o no una pareja, tengan o no hijos, y si los tienen, sean bebés, niños o ado- 
lescentes. Pero hay una gran diferencia con los varones. Las mujeres no abandonaron su jornada de amás de casa, por lo tanto se convirtieron en agentes de "doble jornada". Y en esto la Argentina no está sola. Sigue el camino que ya han recorrido los países más desarrollados de América y de Europa en los que la trayectoria laboral de las mujeres se ha asimilado a la de los varones. Pero no ha ocurrido lo mismo con la "jornada doméstica" de ellos, pocos son los que la han incorporado, y esto muy poco.

Como consecuencia, el modelo tradicional de las familias de "único proveedor (varón)"1 se hizo menos frecuente, en tanto aumentó su frecuencia el modelo de las familias de "dos proveedores". En el Área Metropolitana de Buenos Aires, la aglomeración mayor y más moderna de la Argentina que concentra un tercio de la población del país, los datos son muy elocuentes. Entre 1980 y 1994, en los hogares nucleares completos, el modelo del "proveedor varón único" (esposo activo y esposa inactiva) decreció $23 \%$, de 68 a 52\%, en tanto el de "dos proveedores" aumentó 68\%, desde 23 hasta 38\%. Durante el mismo periodo, el tipo más crítico del modelo del proveedor único (esposo desocupado o inactivo y esposa jefa de hogar) más que se duplicó: de 1.7 a 4.9\%. ${ }^{2}$ El cambio implica una transformación social casi revolucionaria, una que pone en cuestión los valores establecidos acerca de la división del trabajo por género en la sociedad. Sus consecuencias aún no se han evaluado en toda su magnitud.

La posibilidad de las mujeres de obtener y controlar su propio dinero y su independencia, aunque precaria, es un motor de cambios en la distribución del poder conyugal, en la toma de decisiones, en la educación de los hijos y, por supuesto, en la formación y disolución de las familias. Por eso las transformaciones que reseñé se han dado juntamente con transformaciones sociales que tuvieron profundos efectos sobre la estructura familiar. Nuevas formas de vivir en familia han aparecido, o se han extendido a otros sectores sociales, en las últimas dos décadas (Wainerman y Geldstein, 1994). Esto es resultado de la disminución del número de miembros; el aumento de uniones

${ }^{1}$ El modelo, que cristaliza tras la revolución industrial, responde a una división rígida entre un esposo/padre proveedor exclusivo del sustento económico y una esposa/madre proveedora exclusiva del mantenimiento del hogar y el cuidado de los hijos (véase Bernard, 1981; Pleck, 1987).

${ }^{2}$ Los datos provienen de varias ondas de la Encuesta Permanente de Hogares relevadas por el Instituto Nacional de Estadística y Censos (INDEC) de la Argentina, procesadas por gentileza de Alicia Gómez. 
consensuales; la postergación de la edad para casarse; la pérdida de popularidad del casamiento civil, ni qué hablar del religioso; el reemplazo por uniones de hecho, sin papeles; la celebración de bodas de novias embarazadas; el nacimiento de hijos extramatrimoniales; el aumento de separaciones y divorcios. Estos ingredientes han auspiciado la multiplicación de parejas que eligieron no tener hijos; de mujeres solteras que, en cambio, eligieron tenerlos y criarlos solas; de hogares formados por parejas homosexuales o por parejas heterosexuales que adoptaron uno o dos hijos; de familias formadas por una madre y sus hijos, sin padre conviviente; de otras formadas por padres separados, que comparten la tenencia de sus hijos y conviven con ellos en sus respectivos domicilios la mitad de la semana; de hogares formados (muchos menos) por un padre y sus hijos; de hogares "ensamblados" o "reconstituidos", de hogares encabezados por mujeres que son las principales proveedoras económicas.

Se trata de cambios que han acompañado a la autonomía de las mujeres en el mercado de trabajo, a la marcha del movimiento feminista y a la ruptura de la relación entre sexualidad y procreación, a partir de la introducción de la píldora. El amor romántico, en el que la atracción sexual y los afectos prevalecen sobre las conveniencias familiares en la elección de las parejas maritales, también fue una consecuencia. La sexualidad "plástica", como llama Giddens (1992) a la separada de las consecuencias reproductivas, fue otra. Estos movimientos se dieron en un clima de valores que entronizó el individualismo y la autonomía y, por sobre todo, la realización personal. Se consagró entonces el derecho a ser íntegramente uno mismo, a desarrollar al máximo las propias capacidades, afirmando las diferencias, respetando los deberes para consigo mismo antes que para la colectividad y las tradiciones. En este clima de ideas, la psicología ha predominado por sobre la ideología, la diversidad sobre la homogeneidad, lo permitido sobre lo coercitivo, la felicidad sobre la obligación y el sentimiento sobre el deber.

Aún no sabemos en qué medida las transformaciones reseñadas han tenido efecto sobre la dinámica familiar, en particular, en lo relativo a la participación de las mujeres y de los varones en los roles familiares. Es decir, en qué medida la asunción del doble rol por un número creciente de mujeres, y de mujeres con cargas de familia, está siendo acompañada por una mayor participación de los hombres en el tiempo de trabajo doméstico y del cuidado de los niños. En qué medida el rol de padre exclusivamente definido como "pro- 
veedor" está siendo redefinido para incluir también el de "amo de casa" y de "padre". En qué medida en la Argentina estamos asistiendo también a una "revolución estancada", como describe Hochschild (1989) a la originada en el aumento de mujeres con "doble jornada" no acompañado por un aumento equivalente de la participación de los varones en la domesticidad. O en qué medida estamos asistiendo al advenimiento de las "nuevas familias" de Goldscheider y Waite (1991) en las que los esposos han asumido parte del segundo rol, adicionando al de proveedor económico el de partícipe de las tareas del hogar y del cuidado de los hijos. Éstas son preguntas acerca de las relaciones mutuas entre los cambios en el ámbito familiar (estructura y dinámica) y en el laboral, formuladas desde una perspectiva de género.

Comenzamos a responder estas inquietudes a partir de un corto número de familias de los sectores medios integradas por cónyuges con altos niveles de educación. Lo hicimos porque estos sectores están a la cabeza de los cambios de valores, de modo que podrían mostrar más claramente que otros și éstos se habían producido. Preferimos familias de dobles proveedores porque en ellas las mujeres, y en cierta medida los varones, están sometidos a mayores demandas de tiempo, y a mayores demandas de articulación entre la vida familiar y la laboral. Así, en el curso de 1996 entrevistamos separadamente a ambos miembros de 35 parejas conyugales que encabezaban familias de dobles proveedores, de sectores medios, residentes en el Área Metropolitana de Buenos Aires. ${ }^{3}$ Indagamos su discurso y su comportamiento, el plano de lo ético y de lo émico, respecto de la división del trabajo por género en el hogar, tanto en lo doméstico como en el cuidado de los hijos. También indagamos sus imágenes, representaciones y actitudes acerca del género, la paternidad y la maternidad, y la pareja conyugal. Para poner el retrato en perspectiva histórica, indagamos lo que ocurría y los modelos que tuvieron en materia de división del trabajo por género en sus hogares de origen, entre sus progenitores, cuando los entrevistados tenían 10 u 11 años de edad. Con estos datos, estamos en condiciones de explorar para este particular conjunto de familias de sectores medios profesionales, las siguientes preguntas:

${ }^{3}$ La recolección de datos estuvo a cargo de estudiantes avanzadas de sociología, de sexo femenino. Una de ellas, Mariana Heredia, asumió además el rol de asistente de investigación, el que desempeñó con gran capacidad y destacable eficiencia. 
1) ¿Cuáles son las imágenes, percepciones y actitudes de los y las cónyuges acerca del género, la familia y el trabajo, y de sus interacciones?

2) ¿Cómo han organizado la división del trabajo reproductivo en sus hogares entre ambos miembros de la pareja conyugal?

3) ¿Cuánto reproducen los cónyuges de la generación de hoy la división del trabajo que habían establecido sus progenitores en la generación anterior?

4) ¿En qué medida ambos cónyuges tienen imágenes y percepciones compartidas acerca de la realidad de sus hogares?

\section{El escenario y los(las) actores}

Familias actuales y familias de origen

La selección de las 35 familias que entrevistamos fue intencional. Logramos contactarlas a través de amigos, conocidos, compañeros de trabajo y estudio, mediante la estrategia de la bola de nieve. Los criterios de selección fueron: familias nucleares completas, de sectores medios profesionales, con hijos pequeños, en las que ambos cónyuges estuvieran ocupados en el mercado de trabajo.

La edad promedio de las mujeres era de 33.5 años y la de sus esposos, de 35 . Ambos cónyuges tenían altos niveles de educación: $80 \%$ de ellos y $89 \%$ de ellas, al menos universitaria incompleta. Tenían en promedio 1.9 hijos corresidentes, con una edad media de 5.9 años. La mayoría de los niños de dos y más años de edad estaban en el sistema escolar, en el jardín de infantes o en el nivel primario. Casi dos tercios de las familias tenían ayuda doméstica remunerada por un número de horas que variaba entre tres y 80 semanales. Pocas parejas dijeron contar con ayuda familiar (en la mayoría, de sus madres y abuelas) para cuidar a los bebés, para llevar y traer a los niños de la escuela, o para quedarse con ellos en caso de estar enfermos.

Todos los esposos y esposas estaban en el mercado de trabajo, como ocupados, los primeros 50 horas semanales promedio (entre 25 y 80 horas), y las segundas poco más de la mitad, 27 horas semanales (entre 6 y 60). En suma, los varones trabajaban diariamente unas 4.5 horas promedio más que las mujeres. Entre ellas, la mitad (16) trabajaba menos de 25 horas semanales y menos de un cuarto (7), 40 horas y más. Ninguno de los esposos, en cambio, trabajaba menos de 24 ho- 
ras semanales y dos tercios lo hacían por 50 y más horas. En alrededor de un cuarto de las parejas, ambos cónyuges trabajaban tiempo completo. Todos ellos tenían ocupaciones de clase media. Había maestras, profesoras, psicólogas, médicas y empleadas administrativas entre las esposas, y agentes de seguros, empleados de banco, abogados, arquitectos, psicólogos, médicos, comerciantes, entre los esposos.

Ambos se habían criado mayoritariamente en hogares de clase media y media alta, con residencia en el Área Metropolitana de Buenos Aires, sólo muy pocos en hogares de clase baja. Una porción importante tenía un grado de religiosidad (católica) considerablemente alto. Un $70 \%$ de ambos progenitores había alcanzado al menos el nivel de educación secundaria incompleta pero, a diferencia de lo que habría de ocurrir entre sus hijos, con fuertes diferencias entre varones y mujeres en su acceso a los niveles más altos de educación. Sólo $20 \%$ de las madres frente a $44 \%$ de los padres había logrado el nivel de educación universitaria incompleta y completa. El cambio intergeneracional es notable, y no sólo en la expansión de la educación, sino también en la igualación de las oportunidades para ambos géneros. Las cifras son claras: mientras $91 \%$ de las mujeres que entrevistamos poseía los más altos niveles de educación, sólo $20 \%$ de sus madres lo había logrado, un cambio intergeneracional mucho más dramático que entre los varones. Mientras $80 \%$ había llegado a los más altos niveles de educación, sólo poco más de la mitad de sus padres $(45 \%)$ lo había logrado.

Algo más de un tercio de las madres de la generación anterior estaban en el mercado de trabajo, lo que es una tasa de actividad (41\%) relativamente alta para mediados de los setenta. Entonces, la tasa de actividad de la población femenina de la que provenían - mayoritariamente sectores medios, de entre 35 y 45 años de edad, con educación secundaria, casadas, con cónyuge y dos o más hijos en el hogar, rondaba entre 34.0 y $36.5 \%$ (Wainerman, 1979). Ellas trabajaban como maestras, empleadas administrativas, pequeñas comerciantes, familiares sin remuneración en taller o péqueño comercio de su maridos. Éstos eran terratenientes, arquitectos, médicos, abogados, miembros de las fuerzas armadas, comerciantes, empleados administrativos y, eventualmente, trabajadores calificados. Cuando nuestros entrevistados tenían 10 u 11 años de edad, en poco más de la mitad de sus hogares había personal de servicio doméstico. De ellos, unos dos tercios estaban contratados de tiempo completo ( $\sin$ retiro), por más de 35 horas semanales; sólo muy pocos contaban con personal de poco 
tiempo semanal (menos de 16 horas). Las cifras contrastan con las de los hogares actuales, en los que todas las mujeres están en el mercado de trabajo, y algo menos de la mitad no tiene ayuda doméstica remunerada alguna y, por el otro lado, son muy pocos los hogares con servicio doméstico de tiempo completo. Además, mientras en los hogares actuales hay una clara asociación entre el tiempo de trabajo de las mujeres y el del servicio doméstico remunerado, lo que sugiere que las esposas/madres de hoy pagan su reemplazo como tales, nada así ocurría entre sus madres. Entre las que eran amas de casa exclusivamente, poco más de un tercio tenía ayuda doméstica remunerada y, entre las que estaban en el mercado de trabajo, sólo cerca de la mitad tenía ayuda doméstica, el resto no.

La mayor educación de las entrevistadas de hoy, y la similitud con sus maridos en relación con sus progenitores, sumado a la mayor tasa de actividad económica de ellas relativa a la de sus madres, brinda confianza en la relativa validez de la selección de entrevistadas(os), a pesar de que fue intencional y no probabilística. Las diferencias entre las tasas de actividad de las madres y los padres, las ocupaciones en que se insertaban las y los activos, el número de hijos tenidos y conviviendo con los progenitores, todos son consistentes con las cifras que caracterizaban a los sectores sociales medios y altos hace dos o tres décadas, lo que agrega confianza en la validez de la muestra de progenitores indagada.

\section{Lo que ellas y ellos dicen creer}

\section{Acerca del género}

¿Cuál es el mundo de las imágenes, percepciones y actitudes de nuestras entrevistadas y entrevistados respecto de la pareja y de sus respectivos roles de esposos y de progenitores en la familia? Para indagarlo recurrimos a diversos estímulos: frases incompletas, afirmaciones respecto de las cuales expresaron su acuerdo o desacuerdo, y pedido de opiniones explícitas.

Como el foco de nuestra problemática es la interacción de familia, trabajo y género, comenzamos por explorar la concepción de género de nuestros entrevistadas y entrevistados. Para ello recurrimos a un estímulo sobre el cual pudieran proyectar si concebían las diferencias entre hombres y mujeres como obedeciendo al orden natural, es decir, a la biología, o bien al orden cultural, o sea, a la construcción 
que la sociedad ha hecho de sus capacidades respectivas. En otras palabras, indagamos si creían en la existencia de características "esencialmente" femeninas y masculinas, de carácter innato, o si creían que es la socialización de género la que determina preferencias diferentes entre hombres y mujeres. Lo hicimos en el mundo del trabajo, pidiendo nos dijeran si concebían a una serie de ocupaciones como teniendo "marca genérica", es decir, si a su criterio su desempeño requiere características femeninas o masculinas específicas.

Para conocer la concepción de género de las y los entrevistados escogimos nueve ocupaciones y les preguntamos quiénes, en su opinión, podían desempeñarlas mejor, las mujeres, los varones o ambos por igual. Las ocupaciones elegidas fueron las de maestro(a), enfermero(a), recepcionista de oficina, secretario(a), dentista infantil, entre las consideradas socialmente "femeninas", y las de piloto de aviones, jefe (a) de personal, cirujano(a) y pediatra, entre las consideradas "masculinas". A ellas añadimos otras dos, también marcadas por el género aunque pensábamos que con menor intensidad: dentista infantil y cirujano. ${ }^{4}$

En la Argentina, como en la mayor parte del mundo, la fuerza de trabajo está segregada por género. Mientras los varones encuentran espacio en una amplia gama de actividades, las mujeres se concentran en unas pocas, especialmente en los servicios de salud, educación y en los personales, especialmente en los de tipo doméstico. Las razones son dobles, económicas y culturales. Las mujeres han ido a engrosar las ocupaciones menos calificadas y peor remuneradas porque tenían menor educación y entrenamiento que los varones, y porque eran consideradas trabajadoras secundarias, con menores necesidades económicas y menor capacidad de defensa de sus condiciones de trabajo. Las razones de orden cultural llevaron a las mujeres a ocuparse en actividades que parecen extensiones del rol de madre y ama de casa, como maestras, enfermeras, sirvientas.

No obstante, para nuestra sorpresa, una mayoría cercana a los dos tercios de las y los entrevistados dijeron que ser mujer o varón no establece diferencias en las capacidades para desempeñarse en la mayoría de las ocupaciones por las que les preguntamos (siete sobre nueve). La neutralidad genérica está más extendida entre las mujeres que entre los varones. Mientras en $68 \%$ de los casos las mujeres dije-

${ }^{4}$ Sobre la universalidad de estos estereotipos de género ligados a la segregación ocupacional, aun en países como los nórdicos, con elevada conciencia de género y políticas en favor de la igualdad de ambos sexos, véase Anker (1997a y 1997b). 
ron que "ambos por igual" tienen capacidades para desempeñarse en el total de las nueve ocupaciones conjuntas, esta cifra se redujo a $58 \%$ entre los varones. Es decir, ellos apuestan más a la "natura" (antes que a la "nurtura") que ellas. Hay que decir, sin embargo, que cuando atribuyeron una marca genérica, el consenso fue muy alto, ellas y ellos coincidieron en las mismas ocupaciones (véase el cuadro 1). ${ }^{5}$

Es difícil saber si las diferencias que encontramos entre ambos géneros se debe a un prejuicio sexista más extendido entre ellos, o a un deseo de alcanzar mayor igualitarismo por parte de ellas, coherente, por otro lado, con las muestras que están dando las mujeres de invadir ocupaciones antes masculinas. Es que ambos dieron respuestas sólo en parte formadas por sus propias opiniones y, en otra parte, por su constatación de la segregación genérica que de hecho ocurre en la fuerza de trabajo, más su deseo de aparecer "igualitarios" ante las entrevistadoras, todas mujeres. Las ocupaciones que resultaron más neutras genéricamente, es decir, juzgadas susceptibles de ser desempeñadas con igual capacidad por mujeres y varones, son las de maestra(o), pediatra y jefe de personal; les siguen las de enfermero(a), secretario(a) y cirujano(a). Aquellas que resultaron más marcadas genéricamente son la de recepcionista, atribuida a las mujeres (por $83 \%$ de los varones y por $\mathbf{5 4 \%}$ de las mujeres) y la de piloto de aviones, atribuida a los varones (por 57\% de los varones y $54 \%$ de las mujeres).

La de recepcionista despertó la imagen de la "mujer objeto decorativo", la "mujer adorno". Se la concibe como una ocupación-vidriera y, para ello, las cualidades de la mujer objeto parecen ideales. Se trata de buenos modales, buena imagen, buena presencia y de que, en comparación con los hombres, ellas son lindas, agradables a la vista, seductoras, dulces, detallistas, sutiles, amables, pacientes, corteses, cordiales, graciosas. La preferencia femenina en esta actividad, definida como decorativa y como no requiriendo eficiencia ni capacitación, se sintetiza en que "es mucho más lindo sentir un perfume de mujer que ver a un bigotudo al entrar a una oficina".

${ }^{5}$ Los resultados son muy similares a los hallados por Pantelides, Geldstein e Infesta (1995) a comienzos de los noventa en entrevistas con adolescentes de ambos sexos, de entre 15 y 18 años de edad, residentes en el Área Metropolitana de Buenos Aires. También estos jóvenes, con muy pocas excepciones (herrería, cuidado de chicos y pilotaje de aviones), en su mayoría consideraron que mujeres y varones tienen iguales condiciones para la ingenieria, la odontología, el diseño de modas, la gerencia de empresas, la docencia y la venta en negocios. Y también fueron las mujeres más insistentes que los varones en la igualdad de capacidades. 
CUADRO 1

Atribución de marca genérica a las ocupaciones según sexo de personas entrevistadas (porcentajes)

\begin{tabular}{|c|c|c|c|c|}
\hline \multirow[b]{2}{*}{ Ocupaciones } & \multicolumn{3}{|c|}{ Marca genérica } & \multirow[b]{2}{*}{ Total } \\
\hline & Femenina & Masculina & Neutra & \\
\hline & \multicolumn{4}{|c|}{ Mujeres } \\
\hline Dentista & 31.5 & 8.5 & 60.0 & $(35)$ \\
\hline Piloto & - & 54.0 & 46.0 & (35) \\
\hline Maestro(a) & 6.0 & 3.0 & 91.0 & (35) \\
\hline Enfermero(a) & 28.5 & 3.0 & 68.5 & (35) \\
\hline Recepcionista & 54.0 & - & 46.0 & (35) \\
\hline Jefe (a) de personal & 3.0 & 14.0 & 83.0 & (35) \\
\hline Pediatra & - & 17.0 & 83.0 & (35) \\
\hline Cirujano(a) & - & 29.5 & 70.5 & (34) \\
\hline Secretario(a) & 37.0 & - & 63.0 & (35) \\
\hline \multirow[t]{2}{*}{ Total } & 18.0 & 14.0 & 68.0 & $(314)$ \\
\hline & \multicolumn{4}{|c|}{ Varones } \\
\hline Dentista & 48.5 & 8.5 & 43.0 & $(35)$ \\
\hline Piloto & - & 57.0 & 43.0 & (35) \\
\hline Maestro(a) & 20.0 & - & 80.0 & (35) \\
\hline Enfermero(a) & 34.0 & - & 66.0 & (35) \\
\hline Recepcionista & 83.0 & - & 17.0 & (35) \\
\hline $\operatorname{Jefe}(\mathrm{a})$ de personal & 8.5 & 23.0 & 68.5 & $(35)$ \\
\hline Pediatra & - & 15.0 . & 85.0 & (34) \\
\hline Cirujano(a) & - & 34.0 & 66.0 & (35) \\
\hline Secretario(a) & 48.5 & - & 51.5 & $(35)$ \\
\hline Total & 27.0 & 15.0 & 58.0 & $(314)$ \\
\hline
\end{tabular}

Las razones por las que prefirieron a los hombres en la ocupación de piloto de aviones tienen que ver con cualidades que los estereotipos de género suponen más frecuentes entre ellos. Se trata de frialdad, decisión, carácter, lucidez, racionalidad, calma, severidad, determinación, audacia, capacidad para enfrentar riesgos. Quienes consideran que las mujeres son inadecuadas para pilotear aviones les asignan falta de reflejos y exceso de emotividad. A estas características "naturales" añaden que las condiciones de trabajo de la ocupación entran en fuerte competencia con el ejercicio de la maternidad porque impone frecuentes ausencias y, por lo tanto, separaciones de los hijos o, "si la mujer no durmió porque tuvo que cuidar a los hijos, se 
cae el avión". La actividad se define como riesgosa, y tampoco se demanda capacitación.

En suma, a juzgar por este primer abordaje, más de la mitad de nuestros entrevistados(as) están sensibilizados a las cuestiones de género, rechazan los estereotipos vigentes y se adhieren a la igualdad de capacidades y de habilidades de mujeres y varones.

\section{Acerca de la familia}

Nos aproximamos a conocer el mundo de las representaciones de nuestros entrevistados(as) acerca de la familia instándolos a completar dos pares de frases: "En la familia al esposo (esposa)' le corresponde...", y "Una madre (padre) ideal es la (el) que...". Ésta era una segunda oportunidad para conocer la ideología de género de nuestros entrevistados, ahora en relación con la familia.

Comencemos por los roles en la pareja. Para la mayoría de las mujeres y de los varones el rol del esposo en la familia apareció íntimamente ligado al de agente productor y proveedor económico, en primer lugar, y al de quien da seguridad y brinda protección y contención a la familia. En el discurso de las y los entrevistados el término "económico" fue utilizado cuatro veces más frecuentemente en relación con el esposo que con la esposa. Una porción significativa de otras respuestas, más frecuentes entre ellas que entre ellos, subraya la necesidad de que los esposos compartan responsabilidades con sus esposas. La referencia predominante son los hijos, pero mientras los varones entienden por responsabilidades de los padres su educación, las mujeres entienden, además, compartir sus cuidados cotidianos.

El rol de esposa evoca en ambos la realización de la domesticidad y de la maternidad. Organizar la casa, cuidàr y brindar amor y respeto a los hijos son los conceptos de mayor frecuencia en los discursos de ellas. También las cualidades de ternura, paciencia, comprensión. En el discurso de ellos, el papel (también) central que le asignan a la maternidad tiene un matiz diferente, no se trata sólo de los cuidados cotidianos (como dicen ellas), sino también de la educación y de la formación intelectual y moral de los hijos.

Una cierta porción de las parejas entrevistadas destacó la necesidad de que las esposas y los esposos compartan responsabilidades y obligaciones dentro y fuera del hogar, pero el significado que le atribuyeron fue algo diverso según quién y respecto de quién lo hicieran. 
Las mujeres (y no los varones) se adjudicaron la responsabilidad de contribuir al presupuesto familiar con su trabajo remunerado, aunque subordinándolo a la maternidad, y concibiéndolo como un ingreso secundario. También entre las responsabilidades compartidas aludieron reiteradamente al deseo de que los esposos compartan, asuman, las tareas domésticas y, sobre todo, el cuidado de los hijos.

En cuanto a la maternidad y paternidad ideales, ambos cónyuges dijeron desear lo mismo de la madre y del padre: que quieran a sus hijos, que los entiendan, que sepan qué les pasa, que los escuchen, que los cuiden, que los eduquen. Pero más allá de estas similitudes, plantearon diferencias bien marcadas. De una madre ideal esperan que se "reparta" bien entre los hijos, el marido y el trabajo (que sea una "mujer orquesta"); que "deje crecer a los hijos en libertad" (enseñándoles a ser independientes, a tener un proyecto personal), y que tenga paciencia. De un padre ideal, a su vez, dijeron que esperaban que dedicara tiempo a sus hijos llevándolos de paseo, hablando, jugando con ellos; que se preocupara por su bienestar afectivo y económico, que los educara con el ejemplo, que fuera un "modelo" para ellos, y que les brindara protección.

En el discurso que utilizan respecto de la madre aparecieron términos como: cuidar, atender, comprender, entender, escuchar, querer, amar, tener paciencia. En el que utilizaron respecto del padre, en cambio, aparecieron: guiar, proteger, apuntalar, aconsejar y compartir.

Hochschild (1989: 15) elaboró tres tipos de ideología de género según la esfera con que mujeres y varones quieren identificarse (hogar o trabajo) y según cuánto poder en el matrimonio quieran tener cada cual. De la combinación entre ambas surgen tres tipos de ideología: "tradicional pura", "igualitaria pura", y "transicional". Son del primer tipo las esposas(os) que quieren que la mujer se identifique esencialmente como madre y esposa, y que el varón se centre en el trabajo y tenga más poder. Son del segundo tipo, las mujeres/varones que quieren que ambos cónyuges se identifiquen con las mismas esferas (se trate del hogar, la carrera o el hogar y la carrera) y que ambos tengan igual poder en el matrimonio. Finalmente pertenecen al tercer tipo, las parejas en las que las mujeres quieren identificarse con ambos ámbitos, el trabajo y la familia, y los varones lo consienten, bajo ciertas condiciones. En este caso, mientras ellas conciben su participación laboral como una "ayuda" al ingreso del marido (pues es él el "verdadero" responsable por el sostén del hogar), ellos aceptan el tra- 
bajo de sus esposas, siempre y cuando ellas sigan cumpliendo puntualmente con sus obligaciones domésticas y familiares.

La mayoría de nuestras entrevistadas y entrevistados participa de la ideología "tradicional" y, eventualmente "transicional" en materia de ideología de género tal como se plasma en sus concepciones de mujeres y varones como pareja conyugal y como progenitores.

\section{Acerca del trabajo}

Tras haber intentado conocer las imágenes ideales sobre los roles de las mujeres y los varones en la familia, abordamos conocer de manera directa la concepción de la división del trabajo en el hogar entre ambos cónyuges. Para ello preguntamos si en caso de tener que elegir, considerarían "preferible que la esposa ayude al marido a desarrollarse en su trabajo, aunque le signifique no desarrollarse ella laboralmente". La mayoría, más entre los varones, estuvo en desacuerdo enarbolando el argumento de la igualdad de derechos de ambos.

La misma postura, aunque más extendida, la tomaron (también algo más los varones) cuando les dimos la oportunidad de expresar su valoración del modelo tradicional de familia patriarcal según el cual "es mucho mejor para todos si el hombre gana lo necesario para vivir y la mujer se ocupa de la casa y de los hijos". La principal razón que subyacía al rechazo de este modelo es el derecho de las mujeres'a asumir la segunda jormada, el second shift. Nadie, ni entre las mujeres ni entre los varones, consideró que pudiera ser deseable que el rol doméstico se redistribuya entre ambos cónyuges, en que los varones tengan igual derecho a añadir un second shift, consistente en participar de las actividades reproductivas, además de las productivas. Es decir, aun cuando la pregunta que formulamos se refería a ambos miembros de la pareja y a ambos roles, el productivo y el reproductivo, las y los entrevistados se refirieron sólo a la mujer y a los problemas y/o consecuencias que le acarrearía "estar todo el día en la casa", no realizarse, no desarrollar sus capacidades, sus potencialidades. Es que para nuestros entrevistados el trabajo de la mujer no es fundamentalmente un generador de ingresos (como sí lo es para el varón), sino de realización personal. Así, mujeres y varones dijeron que "es valioso que la mujer trabaje y desarrolle sus capacidades", "el trabajo no es sólo para vivir sino para desarrollar sus potencialidades y satisfacer sus necesidades personales y autorrealizarse", "la mujer tiene que tener inquietudes 
personales". Es decir, definieron la situación planteada en términos de la conveniencia de la inserción de ellas en el afuera, y nunca la de ellos en el adentro.

Hay que señalar que en los sectores medios, a diferencia de los bajos, se asigna al trabajo de las mujeres el carácter de opcional, no obligatorio, como sí lo es el de los varones. ${ }^{6}$ También se le asigna un carácter secundario, de "ayuda" al sostén económico del hogar, en tanto al varón uno primario (así como, a la inversa, el trabajo doméstico, y algo menos el cuidado de los niños, es visto como opcional y secundario para los varones y lo contrario para las mujeres). También hay que señalar que entre nuestras entrevistadas fueron pocas las que concebían su trabajo como "carrera", la mayoría lo hacía como "actividad complementaria", en el sentido de la caracterización de García y Oliveira (1994). ${ }^{7}$

Los y las pocas que, en cambio, están de acuerdo con la división tradicional de roles en la pareja alegan la necesidad de los hijos de la presencia constante de la madre, o la culpa que sienten (las mujeres) de dejarlos para salir a trabajar.

A pesar de que nadie consideró la posibilidad de que los varones asuman el rol reproductivo cuando las mujeres asumen además el productivo, la casi totalidad estuvo de acuerdo en que "en caso de que ambos cónyuges trabajen, los esposos deben compartir las tareas domésticas y el cuidado de los hijos con sus esposas". Eso sí, para muchos, sobre todo las mujeres, lo doméstico es el cuidado de los hijos, no la casa; responden como padres-madres, no como pareja. Así, una de las entrevistadas nos dijo que "el hombre tiene que cuidar a los hijos, trabaje o no trabaje. Con la casa me arreglo yo"; otra señaló que por "compartir" entendía "la casa no tanto, pero con los hijos, los hijos sí, así pueden estar más tiempo con ellos".

En verdad, en una primera lectura tuvimos la sensación de que tanto las mujeres como los varones respondieron con "el deber ser", con clichés antes que con sus propias actitudes. Los argumentos que enunciaron para avalar la justicia del "compartir" fueron del tipo de

${ }^{6}$ Arriagada (1990) distingue entre la "lógica de la opción" y la "lógica de la determinación" en relación con el trabajo femenino en los sectores medios/altos y en los bajos.

${ }^{7}$ Para quienes lo conciben como "carrera", "el trabajo extradoméstico es fundamental para el desarrollo personal, hacerlo y ganar dinero son parte indispensable de la experiencia vital"(p. 106). "Para quienes es una actividad 'complementaria', lo principal son los hijos y la relación matrimonial. No lo hacen por necesidad económica y no aspiran a ascensos o mejor remuneración" (p. 115). 
"no tiene que recaer en uno solo el trabajo del hogar. El padre y la madre son importantes. No tiene que llevar uno solo el compromiso, la responsabilidad del hogar"; "porque si existen derechos, existen obligaciones... El embarazo lo tienen las mujeres porque Dios lo quiso así, pero después es igual para ambos"; "todo es trabajo de todos, la responsabilidad de una familia es de dos"; "el trabajo y el cansancio es para los dos por igual, así uno no se sobrecarga".

Pero una segunda lectura reveló que quienes así hablaban precedían todos estos argumentos con una condición: la de que ambos cónyuges tuvieran igual cantidad de tiempo disponible. Gran parte de las respuestas estaban formuladas en condicional: "si tienen los mismos horarios, deberían"; "si los dos trabajan tiempo completo..."; "si ambos trabajan todo el día...". Nadie se preguntó por qué el tiempo disponible de los varones es menor que el de las mujeres, respondieron como si el tiempo de trabajo extradoméstico de ellas y de ellos no lo hubieran decidido entre ambos, sino algún ser ajeno a ellos dos, o como si obedeciera al orden natural. Esta condición les permitió diferenciar sin mayor conflicto lo que dicen creer de lo que hacen en la realidad en sus respectivas familias, en las que ellos trabajan más horas fuera del hogar y eso los exime de hacerlo adentro. Como dijo un entrevistado: "sería lo justo [compartir las tareas], pero a veces la comodidad supera la justicia. Si los dos trabajaran por igual, deberían compartir el resto por igual; por suerte yo trabajo más tiempo y no tengo que enfrentarme con esa situación".

El argumento de la disponibilidad de tiempo es la base de una de las explicaciones que más frecuentemente se proponen en relación con la división del trabajo por género en el hogar, junto a otras dos explicaciones, basada en los recursos relativos (educación, ingresos, etc.) de ambos cónyuges, la una, y basada en la ideología de roles genéricos, la otra. Son ya muchos los autores que coinciden en que las evidencias empíricas han refutado esta explicación (Morris, 1990; Hochschild, 1989; Greenstein, 1996, entre otros). Pero más allá de esto, un problema fundamental del argumento de la disponibilidad de tiempo es que no logra dar cuenta de las diferencias de efectos que tienen estas restricciones para las mujeres y los varones. Porque cualquiera que sea la cantidad de tiempo de trabajo remunerado de las mujeres, ellas continúan haciendo (o siendo responsables por) la mayor parte del trabajo doméstico y del cuidado de los niños. Frente a estas evidencias, Shelton y John (1996) concluyen que "el género resulta el determinante más importante del tiempo de trabajo que ningún otro factor" (p. 317). 
Acerca de cuando hay conflicto entre trabajo y familia

Nos preguntamos por la postura de nuestros entrevistados cuando se plantea un conflicto entre las demandas contradictorias de la vida familiar (más específicamente la atención de los hijos) y la vida laboral. Así, los enfrentamos con el conflicto de mujeres que, teniendo hijos pequeños, deben elegir "si aceptar o no un ascenso en su trabajo si les requiere trabajar a veces hasta tarde". También los enfrentamos con el conflicto de varones obligados a elegir entre "un trabajo que les permita un gran ascenso a costa de pasar menos tiempo con sus hijos y otro que no se los permita pero que les deje más tiempo libre".

La frecuencia de "depende" que recibimos nos dio una indicación de las dificultades que les provocó el conflicto planteado. En ambos casos, pero aún más frente al dilema de la mujer-madre-trabajadora, muchos entrevistados no dieron una respuesta rápida, de cliché, sino que expresaron la necesidad de' sopesar las circunstancias: la necesidad económica de la familia en ese momento, el deseo de crecimiento personal de la mujer/varón involucrado, y la edad de los hijos con la consiguiente necesidad de atención por parte de sus progenitores. Poco más de la mitad de las mujeres y los varones estuvieron de acuerdo en que la mujer aceptara un ascenso, aun a costa de sacrificar el tiempo con sus hijos. "Porque tiene derecho a crecer profesionalmente"; "los chicos crecen y se van"; "puede ser para ella una posibilidad que se da en ese momento y después no". Muchos argumentaron que es la calidad antes que la cantidad del tiempo lo que cuenta en la relación de la madre con sus hijos. Prácticamente nadie contempló la posibilidad de redistribuir la atención de los hijos con los maridos. "Cuando son más chiquitos necesitan más de la madre"; "prefiero a mis hijos, hay etapas de los hijos que no las volvés a vivir"; "el varón no puede suplir ese rol"; "pierde momentos en que los hijos la necesitan y ella se lo va a reprochar, o sus hijos".

Frente a este conflicto, más que frente a ningún otro tema, muchas más mujeres tuvieron dificultades de escoger una respuesta. No sorprende dado que es un tema sin resolver, que moviliza los sentimientos de culpa de la mayoría de ellas, no así de ellos. Es que, como ha señalado Presser (1995), el conflicto real de la mujer entre el tiempo dedicado a su trabajo extradoméstico y el dedicado al cuidado de los hijos es consecuencia del doble estándar de paternidad que evalúa al tiempo de la maternidad como más importante que el de la paternidad. Lo que en realidad hace que el verdadero conflicto sea entre 
los intereses de las mujeres y los de los varones, y no entre los de las mujeres y los hijos.

También en caso del conflicto del varón, poco más de la mitad de las mujeres y los varones favorecieron la elección del ascenso laboral argumentando que más adelante, desde una mejor situación económica, podrían compensar el tiempo robado a sus hijos en el presente. "Yo hoy me estoy sacrificando para tener más tiempo y más dinero en el futuro"; "tenés que saber perder un poco de familia para darle todo a la familia", es lo que nos dijeron.

A pesar de la similitud de posturas ante el conflicto enfrentado por la mujer y por el varón, hay diferencias. Las mujeres tienen más dificultades en expresar su acuerdo o desacuerdo llano, más entre ellas que entre ellos se inclinan por responder "depende" frente al conflicto que las involucra como madres-trabajadoras. También se inclinan más que ellos a su turno por aceptar la decisión del esposo cuando el conflicto los involucra como padres-trabajadores, pasándoles a ellos la responsabilidad o reconociendo/reforzando su poder de decisión. Además, ellas argumentan más frecuentemente a partir de la necesidad de los hijos de tener a su madre en los primeros años de vida, en tanto los varones lo hacen más a partir de las necesidades económicas de la familia.

Finalmente enfrentamos a nuestros entrevistados con un caso concreto de conflicto familiar-laboral centrado en el valor relativo del trabajo de ambos miembros de la pareja. Les planteamos la situación de que ambos "padres trabajen y tengan que asistir a una reunión en la escuela de los hijos". La disyuntiva era si era "mejor que fuera la madre y no el padre quien faltare a su trabajo". Aquí, entonces, el conflicto no es entre el tiempo de los hijos y los del trabajo, sino entre el tiempo de trabajo del esposo y la esposa. En este caso la respuesta fue mayoritariamente favorable a la igualdad de ambos. Quienes aceptaron que fuera la mujer quien cediera su trabajo, argumentaron acerca de la cantidad de tiempo disponible, o de la flexibilidad de los horarios de trabajo. Como ante la opinión acerca del deber del marido de compartir las tareas domésticas con la esposa cuando ambos trabajan, nadie cuestionó por qué son las mujeres las que disponen de más tiempo que los varones, por qué más entre ellas que entre ellos participan de la fuerza de trabajo a tiempo parcial y/o con horarios flexibles.

Vale la pena destacar que varias entrevistadas mencionaron que está mal visto socialmente que el varón falte a su trabajo por una 
cuestión familiar, no así que lo haga la mujer. Es que, como lo postuló Pleck (1976-1977), existen límites permeables asimétricos entre los roles laborales y familiares para mujeres y varones de tal modo que a ellos se les permite que las demandas del rol laboral se entrometan en el rol familiar más que al revés, en cambio a ellas se les permite que las demandas del rol familiar se impongan sobre el rol laboral más que al revés.

En suma, una primera lectura de las respuestas de los entrevistados en el nivel de superficie nos devolvió una imagen en la que predominaba un discurso en favor de la igualdad de derechos y oportunidades para ambos miembros de la pareja no sólo aceptando sino además valorando el trabajo femenino, abogando por una división igualitaria de las responsabilidades domésticas, acordando en la necesidad de que los varones asumían un rol más inactivo con respecto a sus hijos. Una segunda lectura en el nivel profundo descorrió el velo sobre matices y sobre los mitos que encubren la real desigualdad entre los cónyuges en la domesticidad. Los mitos naturalizan las diferencias de'disponibilidad de tiempo de esposas y esposos, así como la división del trabajo en la familia y entre los roles productivo y reproductivo.

\section{Dichos y hechos}

Confrontamos a ambos cónyuges de las 35 parejas separadamente con una serie de actividades que se realizan en sus hogares y les pedimos nos dijeran quiénes las hacían. Lo formulamos de la siguiente manera: "¿Diría usted que hace todo, la mayor parte, parte, algo, o nada de cada una de las siguientes actividades?"

En el ámbito doméstico las tareas eran: cocinar, lavar los platos, poner y recoger la mesa, lavar la ropa, planchar, limpiar, la casa, hacer las compras, pagar las cuentas, ocuparse del mantenimiento del auto, hacer pequeñas reparaciones de grifería y plomería, arreglar enchufes, contratar a un pintor, carpintero o plomero, y arreglar salidas con amigos. En cuanto al cuidado de los niños, preguntamos por: cambiar pañales, dar de comer, bañar, vestir, hacer dormir, hacer que se cepillen los dientes, llevarlos a la escuela, ayudarlos con las tareas escolares, preparar la fiesta de cumpleaños, hablar con los maestros, asistir a reuniones de padres en la escuela, reprenderlos, quedarse en casa cuando están enfermos, llevarlos al médico, y comprarles ropas. 
Como dijimos en otro lugar, ${ }^{8}$ entre las 35 parejas conyugales que entrevistamos, las tareas domésticas en el hogar están fuertemente segregadas por género, lo que significa que los varones no participan del second shift (doble jornada). Para decirlo de otro modo, hay tareas, la mayoría en verdad, que "no son tareas de hombres". Son aquéllas en las que entre 90 y $100 \%$ de los varones no participan nada, o apenas algo. Son parte de la rutina cotidiana o de realización muy frecuente: cocinar, lavar los platos, limpiar la casa, lavar la ropa, planchar. A su vez, son escasas las actividades que "no son tareas de mujeres". Cuando se trata de algunas tareas ocasionales -como pequeñas reparaciones domésticas o el mantenimiento del auto, quienes tienen uno-, los hombres hacen todo o la mayor parte, y las mujeres poco o nada. ${ }^{9}$

La situación es diferente en el ámbito del cuidado de los hijos. En primer lugar, son muchas menos las parejas, y en relación con relativamente menos actividades, en las que existe una definida segregación genérica, que aquellas que comparten la maternidad-paternidad. En segundo lugar, cuando existe segregación, toma la forma de los padres haciendo nada o sólo algo y las madres haciendo todo, como en lo doméstico. Pero, a diferencia de lo doméstico, en este caso las mujeres casi no tienen ayuda de otros en el hogar, sea del servicio doméstico remunerado o de familiares. Fuera de la "función guardería" del sistema escolar, el cuidado y crianza de los hijos es casi responsabilidad exclusiva de los padres. No es transferida ni delegada, excepto cuando se trata de la compra de ropa, de quedarse en casa acompañándolos cuando están enfermos, o llevándolos y trayéndolos de la escuela. En estos casos, las madres pueden ser reemplazadas por un pariente, una persona de servicio doméstico o el transporte escolar. Esta esfera de tareas difiere de las domésticas las que, en muchas familias, las mujeres delegan en servicios pagados (personales o no) que hacen el lavado y planchado de la ropa, la limpieza de la casa, o el arreglo de la plomería o de los artefactos eléctricos.

Cuando se trata de reprender a los chicos, de asistir a reuniones escolares, de llevar a los hijos a ver al médico o, menos frecuentemen-

8 "Men and the Family", ponencia presentada en el seminario Men, Family Formation, and Reproduction, organizado por el Comité de Género y Población, de la International Union for the Scientific Study of Population (IUSSP), Buenos Aires, 13-15 de mayo de 1998.

${ }^{9}$ Las evidencias están contenidas en los cuadros del anexo. Para el análisis optamos por la información de uno solo de los cónyuges: la esposa. 
te, de hacerlos dormir o de vestirlos, entre un medio y tres cuartos de los esposos entrevistados comparten las tareas con las esposas. Pero todo cambia radicalmente cuando se trata de bañarlos, cambiarles los pañales, o ayudarlos con los deberes escolares. En estos casos escasamente un tercio de los padres comparten con las madres. Los otros dos tercios no participan nada o apenas algo, y son las madres las que hacen todo o la mayor parte de estas tareas diarias.

El cambio de pañales es paradigmático. Figura entre las tareas de la crianza más rechazadas. Los hombres pueden llegar a decir "mi religión no me lo permite", y las mujeres relatar que ellos no sólo no cambian pañales sino que ni los tocan porque les da asco.

Vale la pena recordar que lo descrito es la situación de las actividades domésticas y de crianza de parejas conyugales en las que no sólo el esposo-padre, sino también la esposa-madre está en la fuerza de trabajo. Cierto es que mientras la mayoría de ellos trabaja de tiempo completo y más, escasamente un tercio de ellas lo hace. La mitad trabaja medio tiempo y un quinto sólo unas pocas horas a la semana. En todas las familias hay uno o dos, y hasta tres niños pequeños, y sólo menos de la mitad tiene servicio doméstico, un cuarto sólo una, o excepcionalmente dos veces a la semana, por sólo tres a cinco horas diarias.

Tomando en cuenta el grado de segregación genérica entre los cónyuges en las tareas domésticas y del cuidado de los hijos, clasificamos a cada uno de los hogares como "tradicional", "transicional" e "igualitario", siguiendo la clasificación de ideología de género propuesta por Hochschild (1989). Ella lo formuló para describir ideología, nosotros también para el comportamiento.

Definimos a los hogares según la distribución más o menos compartida entre los cónyuges de la ejecución y/o responsabilidad por las tarèas domésticas y, separadamente, según la más o menos compartida en la ejecución de las tareas referidas a los hijos. ${ }^{10}$ Manejamos la definición, para las tareas domésticas, con base en: 1) existencia o no de segregación genérica, y 2) grado en que los esposos comparten tareas "típicamente femeninas" y diarias u ocasionales. Para las tareas del cuidado de

${ }^{10}$ Diferenciamos "ejecución" de "responsabilidad" en el casọ de las tareas domésticas, porque a menudo son compartidas también con personal dọméstico y, en menor medida, con familiares. Cuando esto ocurría, asignamos la responsabilidad a las mujeres si se trataba de açtividades "típicamente femeninas" (lavar, cocinar, etc.) y a los varones si de "típicamente masculinas" (arreglos menores de grifería y plomería, arreglar el auto, etc.). No hicimos tal diferenciación para el cuidado de los hijos porque resultó menos compartida con terceros. 
los hijos, tomamos en cuenta un único indicador: frecuencia de tareas compartidas.por/o plenamente a cargo de varones. La medida era relativa a la edad de los hijos (sólo pequeños, sólo con hijos en edad escolar, hijos de ambas edades), es decir, a las tareas pertinentes a realizar. ${ }^{11}$

Si se atiende a las tareas de la casa, casi todos los hogares son tradicionales $(29 \%)$ o transicionales $(57 \%)$, sólo poco más de $10 \%$ comparte las tareas de manera igualitaria. En cambio, cuando se trata de la crianza de los hijos, no encontramos casi ningún hogar tradicional; la casi totalidad se comportaban como transicionales $(51 \%)$ o como igualitarios (41\%), como puede verse en el cuadro 2. Esto indica, además del mayor igualitarismo en la paternidad-maternidad que en la domesticidad, que sólo en la mitad de los hogares hay coherencia total en la manera de estructurar la división del trabajo en ambas esferas, y esa mayoría está en transición en ambas. En el resto, las parejas han llegado a establecer una división del trabajo más igualitaria o en transición como progenitores que como esposos.

En suma, como se encontró en otros contextos (Dunn, 1997; Durán, 1988; Hass, 1993; Hochschild, 1989; Hood, 1986; Morris, 1990; Ramos Torres, 1990; Szinovacz, 1984; Warshofsky, 1988; Zhang y Farley, 1995, entre otros), en estas familias de dobles proveedores, de sectores medios, la conducta de los varones está menos marcada por el género cuando actúan como padres que cuando lo hacen como esposos. Los varones participan más con los hijos que con el hogar. El ámbito del trabajo doméstico es definido como femenino mientras el de la crianza de los hijos, como una empresa compartida.

Vale la pena notar, como lo ilustra el cuadro 2, que la disponibilidad de tiempo de los cónyuges no es independiente del tipo más o

${ }^{11}$ En el ámbito doméstico, la pareja "tradicional" es una en que la segregación genérica afecta a muchas tareas, y los cónyuges no comparten ninguna o sólo una tarea "típicamente femenina" y ocasional. En la pareja "transicional" la segregación genérica afecta a muchas tareas, pero los cónyuges comparten algunas "típicamente femeninas", aunque de poco tiempo y ocasionales (hacer las compras, arreglar salidas con amigos, etc.). En el caso "igualitario", la frecuencia de tareas segregadas por género son escasas, los esposos participan con cierta frecuencia de tareas "típicamente femeninas" y cotidianas (cocinar, limpiar la casa, etc.) o los cónyuges se distribuyen algunas de estas tareas de manera total.

En el ámbito del cuidado de los hijos, en la pareja "tradicional" el padre no se ocupa de ninguna tarea o sólo de reprender, llevar a la escuela o al médico o de hacer dormir. La "transicional" es otra en la que el padre comparte algunas tareas, en general ocasionales o de poco requerimiento de tiempo. Finalmente, en la pareja igualitaria el padre comparte la mayoría de las tareas, incluso las más "femeninas" (preparar cumpleaños, quedarse en casa cuando el hijo está enfermo, etcétera). 
menos igualitario de división del trabajo en el hogar. Así, la división igualitaria es más frecuente en los hogares en los que ambos cónyuges están en la actividad productiva de tiempo completo que en aquéllos en que las mujeres tienen una inserción de medio tiempo y los varones de tiempo completo. Pero la existencia de esta relación no puede interpretarse lisa y llanamente como evidencia en favor de que es la disponibilidad de tiempo la que posibilita una división del trabajo más igualitaria, la relación podría ser al revés, una en que la división del trabajo entre los cónyuges permite una inserción laboral más igualitaria de ambos cónyuges. Es posible que la relación no responda a una u otra dirección sino que sea simétrica, es decir, de mutua determinación.

GUADRO 2

Tipo de distribución de trabajo doméstico y del cuidado de los hijos según tiempo de trabajo de ambos cónyuges (porcentajes)

\begin{tabular}{lccc}
\hline $\begin{array}{l}\text { Ámbito de tareas } \\
\text { y tipo de división } \\
\text { entre cónyuges }\end{array}$ & $\begin{array}{c}\text { Tiempo de trabajo } \\
\text { completo }\end{array}$ & $\begin{array}{c}\text { Él completo } \\
\text { ella medio }\end{array}$ & Total \\
\hline Doméstico & $(9)$ & $(23)$ & $(32)$ \\
Tradicional & 1 & 39 & 29 \\
Transicional & 56 & 57 & 57 \\
Igualitario & 33 & 4 & 14 \\
& & & \\
Cuidado hijos & $(9)$ & $(23)$ & $(32)$ \\
& & 13 & 8 \\
Tradicional & - & 52 & 51 \\
Transicional & 56 & 35 & 41 \\
Igualitario & 44 & & \\
\hline
\end{tabular}

De los hogares de ayer a los de hoy

Nos aproximamos a indagar los cambios intergeneracionales en la división del trabajo en el hogar pidiend́o a nuestros entrevistados(as) que recordaran cómo era la situación en sus hogares de origen cuando ellos tenían alrededor de 10 u 11 años. Tomando en cuenta las dificultades de recordar lo ocurrido 30 años antes, más el hecho de que 
hay actividades menos públicas (visibles) que otras, para el pasado inquirimos por sólo 18 de las 25 actividades por las que inquirimos para el presente: nueve domésticas y. nueve del cuidado de los hijos.

Con el fin de comparar el grado de participación de los varones, en primer lugar, y de las mujeres secundariameníte, en ambas áreas de actividad, calculamos la tasa de participación de ellos y de ellas en uno y otro conjunto de actividades, en los hogares de origen (de ellas y de ellos) y en los actuales (de ambos). No tomamos en cuenta la intensidad de la participación, sólo la existencia o no de cualquier medida de participación. ${ }^{12}$ Como puede verse en el cuadro 3 , son los varones los que han hecho un gran cambio, y mucho más en su rol de padres que de esposos. En las nueve tareas domésticas por las que preguntamos en el pasado y en la actualidad, la participación de los varones se incrementó en $34 \%$; mientras en las nueve tareas de cuidado de los hijos, se incrementó casi al doble, $63 \%$. La participación de las mujeres se mantuvo casi sin cambio. El panorama es más dramático si se consideran, en el ámbito doméstico, cuánto cambiaron las pautas de división del trabajo alrededor de cinco actividades "típicamente femeninas" y cotidianas como son: cocinar, lavar los platos, limpiar la casa, lavar la ropa y planchar. Según nuestros(as) entrevistados(as), sólo 7\% de sus progenitores contribuían a la realización de esas tareas, en tanto lo hacen tres veces más ( $23 \%$ ) los esposos de hoy. Más notable aún es el aumento de participación de los varones en dos de las tareas más cotidianas: bañar y vestir a los hijos. En este caso, prácticamente ninguno (5.6\%) de los padres de hoy recuerda al suyo bañándolos o vistiéndolos, en tanto la mayoría (64.3\%) de ellos declara hacerlo con sus propios hijos. El incremento es sideral. Tampoco en esta esfera de actividad la participación femenina ha variado.

Hay que advertir que la mayor participación masculina en actividades domésticas en muchos casos sólo significa hacer "algo" de actividades en las que antes los hombres no hacían "nada". Pero hay otras, aunque aún escasas, en las que compartir tareas por partes iguales se ha hecho más frecuente. Tal es el caso de pagar las cuentas o de hacer las compras. Es respecto de la paternidad que el cambio cultural ha sido grande en la última generación. Lo que entonces era casi exclusivamente "maternidad" hoy a venido a incorporarse también a la "paternidad".

12 Es decir, consideramos por igual a quienes hacían "todo", "la mayor parte", "parte" o "algo" de cada una de las actividades indagadas, y a la totalidad de ellos(as) como diferentes a quienes no hacían "nada". 


\section{CUADRO 3}

Tasas de participación en la reproducción doméstica y filial de los hogares, por sexo (porcentajes)

\begin{tabular}{|c|c|c|c|c|c|c|}
\hline \multirow[b]{2}{*}{ Tareas } & \multicolumn{3}{|c|}{ Participación varones } & \multicolumn{3}{|c|}{ Participación mujeres } \\
\hline & $\begin{array}{l}\text { Hogar } \\
\text { origen }\end{array}$ & $\begin{array}{l}\text { Hogar } \\
\text { actual }\end{array}$ & Dif. \% & $\begin{array}{l}\text { Hogar } \\
\text { origen }\end{array}$ & $\begin{array}{l}\text { Hogar } \\
\text { actual }\end{array}$ & Dif. $\%$ \\
\hline
\end{tabular}

Tareas domésticas

$\begin{array}{lrrrrrr}\text { Global }\left(9 \text { tareas) }^{\mathrm{a}}\right. & 34 & 46 & 34.1 & 63 & 70 & 11.3 \\ \text { Fem. cotidianas }^{\mathrm{b}} & 7 & 23 & 212.0 & 79 & 82 & 4.4 \\ \text { Masc. ocasionales }^{\mathrm{c}} & 70 & 80 & 14.0 & 21 & 39 & 89.4\end{array}$

Cuidado hijos

$\begin{array}{lrrrrrr}{\text { Global }(9 \text { tareas })^{\mathrm{d}}}_{\text {Fem. cotidianas }^{\mathrm{e}}} & 40 & 65 & 63.7 & 93 & 93 & -0.5 \\ & 6 & 64 & 1148.0 & 94 & 100 & -0.6\end{array}$

\footnotetext{
a Planchar, lavar la ropa, limpiar la casa, lavar los platos, cocinar, hacer las compras, pagar las cuentas, arreglos de grifería/enchufes/etc., mantener el auto.

${ }^{\mathrm{b}}$ Planchar, lavar la ropa, limpiar la casa, lavar los platos, cocinar.

' Arreglos menores de grifería y plomería, enchufes, etc., mantener el auto.

' Vestir, bañar, ayudar con deberes, reprender, hablar con maestros, llevar al médico, comprar ropa, hacer dormir, llevar a la escuela.

e Bañar, vestir.
}

Las mujeres no sólo no han disminuido casi nada su altísima participación en la domesticidad y en la maternidad, sino que más mujeres han invadido, además, actividades que antes eran dominio casi exclusivo de los varones (arreglos menores de grifería y plomería, arreglar enchufes, etc.). En suma, a la doble jornada laboral, fuera del hogar, que las mujeres han adicionado a sus "tareas específicas" de siempre, han agregado, además, dentro del hogar otras tareas que ahora comparten con sus cónyuges.

Hay que notar diferencias sustanciales entre las mujeres que entrevistamos hoy y sus madres, pertenecientes a la generación anterior. - Mientras que la totalidad de las mujeres de hoy integran la fuerza de trabajo, menos de la mitad de sus madres (41\%) lo hacían, lo que para los años setenta era una elevada tasa de actividad. Pero el hecho es que casi dos tercios de estas mujeres (mayoritariamente de sectores medios, de 35 a 45 años de edad, con educación secundaria) eran amas de casa de tiempo completo cuando sus hijos tenían alrededor de $10 \mathrm{u} 11$ años. Yalgo más de un tercio de ellas tenía empleada domésticas sin retiro. 


\section{Ellas + ellos $=$ dos versiones}

Hasta hace muy poco tiempo era usual en la investigación sobre las familias recoger datos de uno solo de los miembros de la pareja conyugal. Si se trataba de ingresos, el esposo era el elegido; si de fecundidad, la esposa. Cuando estudiamos la dinámica interna de la familia a menudo se entrevista a uno solo de los miembros, por razones esencialmente pragmáticas, no teóricas. Es más simple y menos costoso recoger y analizar datos de una persona por unidad que enfrentar la duplicación de la recolección y el análisis, a más de tener que hacerlo con la coherencia e incoherencia entre los informantes. El presupuesto que subyace a esta práctica es que ambos miembros de la pareja tienen información relativamente similar. ¿Es verdad? Según Hertrich (1997), "se necesitan tres condiciones para que la información se dé de manera adecuada: que la persona conozca los datos, que la recuerde, y que la informe de modo veraz".

¿En qué medida era el caso de nuestros entrevistados(as)? Hubo tres ocasiones en las que pudimos indagarlo; en las tres se trataba de información sobre comportamientos, no sobre opiniones, creencias, valores o actitudes, es decir, sobre hechos "públicos", no latentes. Se trataba del horario y el tiempo de trabajo de la empleada doméstica (en las familias en que la había); del abanico de tareas que se realizan en la casa para el mantenimiento del hogar y la atención de los hijos, y de la participación de cada uno de los cónyuges en la realización de dichas tareas. La pregunta es, entonces, ¿en qué medida la reproducción cotidiana de la familia es una tarea compartida por ambos cónyuges en las familias que estudiamos al punto de compartir o no las percepciones de qué, quién y cuánto ocurre?

Comencemos por examinar en qué medida ambos cónyuges comparten una idéntica versión de cuánta ayuda doméstica remunerada tienen en sus hogares. ${ }^{13}$

No todos los hogares empleaban servicio doméstico, pero algo más de la mitad $(60 \%)$ sí lo hacía. Sólo un tercio de los cónyuges concordó en su percepción; en casi la mitad de los hogares los esposos dijeron disponer de más $(28.5 \%)$ o de menos (19\%) horas de servicio doméstico que sus esposas. El resto de los esposos (19\%) dijo ignorar

${ }^{13}$ Formulamos dos preguntas: "¿tienen ustedes empleada doméstica?" y, a quienes tenían, "¿cuántas horas por semana trabaja la empleada aquí?" 
el tema. ${ }^{14}$ Sigamos ahora con la percepción de las y los esposos, de la demanda de tareas que existe en sus hogares.

Aún viviendo bajo el mismo techo y entre las mismas paredes, hay casos, y no pocos, en los que uno de los cónyuges niega que se realice una tarea que el otro no sólo afirma que se realiza sino que, más aún, es capaz de informar quién o quiénes la realizan. Tal situación es más frecuente en relación con los hijos que con las tareas domésticas, y no sólo en relación con tareas ocasionales sino también con las cotidianas. Alcanzan a un cuarto (nueve parejas) las que mostraron este tipo de incongruencia. Las actividades alrededor de las cuales se suscitaron fueron: dormir a los niños, hacer que se cepillen los dientes, ayudarlos con los deberes, hablar con los maestros, asistir a reuniones escolares. Mientras uno de los cónyuges informó cuán to tiempo le dedica él/ella y cuánto el otro(a), el segundo cónyuge dijo que su hijo(a) era demasiado grande, o aún muy pequeño, como para requerir esos cuidados. ¿Cuál fue el cónyuge que con mayor frecuencia considera no pertinente la tarea en cuestión en su hogar? El esposo, en siete de los nueve casos en los que manifestaron estas diferencias de opinión.

Finalmente, miremos hasta qué punto ambos cónyuges coinciden en sus percepciones de su propia participación y la de su pareja en la reproducción de la familia. Al hacerlo, hay que separar el ámbito de las tareas domésticas de las del cuidado de los hijos porque la situación es diferente en ambos. Se trata del grado de coincidencia o discrepancia del retrato que cada cónyuge dio sobre la división del trabajo, no de los retratos en sí.

La gran mayoría de las parejas (más de 70\%) concordaron en lo realizado por los esposos en cinco de las 12 actividades del cuidado del hogar por las que indagamos. Se trata de las muy segregadas genéricamente, en las que los varones no hacen "nada" o sólo "algo" (limpiar la casa, planchar, lavar la ropa y cocinar), o bien hacen "todo"

14 Nos inclinamos a creer que la percepción de ellas se ajusta más a la realidad dado que fue evidente en las entrevistas que las domésticas comparten, o ayudan en, el hacer sólo con las esposas, nunca con los esposos. Además, frente a las preguntas, ellas dieron respuestas categóricas ("tantas horas por semana", o "de tal a tal hora"); ellos, en cambio, dudaron, indicaron un rango de tiempo más impreciso ("tres o cuatro horas semanales"). Por último, un número nada despreciable de los esposos (casi uno de cada cinco) no contestó la pregunta, sea porque no cumplieron con la consigna, respondiendo por los días de trabajo pero no por las horas, o viceversa sin aclarar la frecuencia semanal ("de 8:00 a 19:00 hrs."), o porque no conocían la situación en sus hogares ("un rato, no sé cuánto"). Nada equivalente encontramos en ninguna de las esposas. 
(mantenimiento del auto). En el resto de las siete actividades la coincidencia acerca de lo que participan los varones fue sólo mediana $o$, excepcionalmente, muy baja (entre 31 y $60 \%$ de las parejas). Y la dirección fue la de ellos sobrestimando su propia contribución respecto de lo que le adjudicaban sus esposas (en general ellos adjudicándose hacer "algo" o "parte" y ellas "nada").

En cuanto a lo realizado por las esposas, sólo respecto de dos tareas (muy segregadas genéricamente: la del mantenimiento del auto y la de arreglos menores de grifería y plomería, y hacer pequeñas reparaciones) en las que en general ellas no participan "nada", una amplia mayoría de parejas concordaron. Respecto del resto de las tareas, entre 40 y $70 \%$ de las parejas no concordaron en su percepción de lo realizado por las mujeres del cuidado de la casa. ${ }^{15}$ Las tareas sobre las que las discrepancias de visiones son mayores fueron: quedarse en casa acompañando al hijo cuando está enfermo, hablar con los maestros, hacerlos cepillar los dientes, hacerlos dormir, o vestirlos.

Donde la ausencia de coincidencia en las percepciones de lo hecho por las unas y los otros resultó realmente elevada, fue respecto del cuidado de los hijos. Posiblemente se deba a que no hay tan alta segregación genérica ni un consenso cultural tan claro como lo hay en el ámbito de lo doméstico; también a que las pautas de división del trabajo alrededor de los hijos están cambiando, son más fluidas. El hecho es que entre un tercio y dos tercios de las parejas no coincidieron en su estimación de la contribución de cada cual al cuidado de los hijos. Yla pauta se repite: los varones tienden a sobrestimar su participación y a subestimar la de sus esposas, una pauta que ha sido encontrada por otros investigadores que, como nosotros, incluyeron la voz de ambos esposos (Berk, 1985; Greenstein, 1996).

Las diferencias de percepción podrían deberse a cuestiones de la validez de las respuestas. Por ejemplo, si los varones, preocupados por presentarse como igualitarios, abultaron su participación. De no ser así, que las percepciones de ambos cónyuges acerca del llevar adelante la reproducción cotidiana de la casa y los hijos sea tan escasamente compartida por las parejas, sugiere reflexiones sobre la vida en familia y sobre cuestiones de método. Respecto de la primera, que la re-

${ }^{15}$ Esto se debe a que en muchas familias las mujeres (pero no los varones) comparten la realización de muchas tareas con el servicio doméstico (y eventualmente con los hijos u otros familiares) cuya contribución en tiempo de trabajo, como dijimos antes, no es percibida igualmente por las y los esposos. 
producción y, más aún la atención de los hijos, no es una empresa de socios igualitarios y, además, que ha de ser fuente de frecuentes conflictos conyugales. ${ }^{16}$ Respecto de la segunda, que la información de uno de los miembros de la pareja no puede adjudicarse como válida para el otro sin más ni más.

\section{Conclusiones}

En el "sistema de roles trabajo-familia" en el que están insertos los miembros de parejas conyugale ${ }^{17}$ se ha producido un gran cambio en las últimas tres décadas en la Argentina en cuanto al rol laboral de las mujeres. Sobre todo las unidas -sea legal o consensualmente-con cargas de familia, han estado entrando en números crecientes a la fuerza de trabajo, y todo hace pensar que seguirán haciéndolo en el futuro próximo. Esta opción que han tomado más mujeres de asumir el rol laboral, además del familiar, no ha tenido una contraparte de igual magnitud entre los varones. La redefinición del lugar de las mujeres en el afuera no ha sido acompañado hasta el momento por una redefinición de igual magnitud del lugar de ellos en el adentro. Para los varones, el tiempo de la paternidad/maternidad aparenta seguir siendo más valioso que el de la domesticidad, así como el de la maternidad más que el de la paternidad y, para ambos, mujeres y varones, el tiempo laboral de ellos que el de ellas.

Es el discurso manifiesto el que ha cambiado mucho, tanto entre las mujeres como entre los varones. Hasta el momento, la sensibilidad a la cuestión de género, a la igualdad de capacidades y de oportunidades, al derecho a la realización personal, al desarrollo individual, se ha adueñado más del discuirso público, que las actitudes más profundas y que los comportamientos. Entre las familias de dobles proveedores de sectores medios y medios altos, con elevados niveles de educación como las que entrevistamos, la división del trabajo se ha alejado del modelo tradicional de roles segregados, para seguir más frecuentemente un modelo transicional, y menos frecuentemente,

${ }^{16}$ Fassinger (1993) señala que "un factor clave que ayuda a perpetuar la desigualdad de género en el hogar es la distinta percepción que hombres y mujeres tienen sobre la responsabilidad por estas tareas". La autora asigna a estas diferencias en las percepciones, la perpetución de la desigualdad de género en el hogar.

${ }^{17}$ Concepto desarrollado por Pleck (1976-1977), compuesto por el rol laboral de la mujer, el rol laboral del varón, el rol familiar de la mujer y el rol familiar del varón. 
por ahora, uno igualitario. Esta visión sincrónica adquiere un matiz promisorio cuando se la ubica en una perspectiva diacrónica, en relación con los cambios recorridos desde el tiempo de los padres, cuando prevalecían los hogares de un único proveedor (masculino). En estos años, los varones incrementaron su participación en las actividades hogareñas, poco en lo doméstico pero mucho en relación con el cuidado de los hijos en comparación con los modelos que vivieron en los hogares donde crecieron. El cambio no fue parejo: la paternidad ha ganado muchos más adeptos que la domesticidad. Ésta sigue siendo definida como femenina, mientras la crianza de los hijos ha comenzado a ser una empresa compartida. A su vez, las mujeres no sólo no disminuyeron su altísima participación en la domesticidad y la maternidad sino que, además, "feminizaron" actividades tradicionalmente masculinas en el hogar.

Todavía es demasiado pronto para dar una respuesta definitiva a la pregunta que nos formulamos inicialmente: ¿revolución estancada o nuevas familias? Las parejas que entrevistamos están compartiendo algo más de las tareas domésticas y mucho más de las del cuidado de los niños que lo que hacían sus padres 30 años atrás. La paternidadmaternidad ha sido redefinida mucho más extensamente que la conyugalidad. Los niños de hoy, socializados en este clima, posiblemente habrán de reproducir, si no apresurar, la tendencia al igualitarismo cuando lleguen ellos mismos a la edad de formar sus propias familias. La incomodidad que detectamos en muchos de los esposos cuando debieron informarnos cuánto contribuyen a la realización de las tareas domésticas y de la atención de los hijos; ofrecen evidencias de las presiones que han estado ejerciéndose recientemente sobre los varones para aumentar su participación en las cuestiones hogareñas y paternales. Las mujeres seguirán entrando a la fuerza de trabajo en el futuro cercano. Como no puede esperarse que todas sean capaces de ser supermujeres, se puede conjeturar que los hombres habrán de incrementar su participación en la casa y la atención de los hijos, compartiendo la carga del segundo turno desempeñado por las mujeres y haciendo que la "masculinidad" no siga igualada de modo exclusivo con la habilidad de proveer económicamente. Por eso votamos por un futuro, si bien no muy cercano, de "nuevas familias". 


\section{Anexo}

CUADRO 1

Participación en actividades domésticas en el hogar actual, versión de ellas, y en el hogar de origen (porcentajes)

\begin{tabular}{|c|c|c|c|c|c|c|}
\hline \multirow{2}{*}{$\begin{array}{l}\text { Participación } \\
\text { en actividades }\end{array}$} & \multicolumn{3}{|c|}{ Hogar actual } & \multicolumn{3}{|c|}{ Hogar de origen } \\
\hline & Ellas & Ellos & Otros & Ellas & Ellos & Otros \\
\hline Cocinar & $(35)$ & (35) & (19) & (63) & $(63)$ & $(22)$ \\
\hline Nada & 3.0 & 60.0 & - & 13.0 & 89.0 & - \\
\hline Algo & 11.0 & 28.5 & 63.0 & 5.0 & 6.0 & 27.0 \\
\hline Parte & 20.0 & 8.5 & 21.0 & 16.0 & 5.0 & 32.0 \\
\hline Mayor parte & 43.0 & - & 16.0 & 9.0 & - & 4.5 \\
\hline Todo & 23.0 & 3.0 & - & 57.0 & - & 36.5 \\
\hline Lavar los platos & $(35)$ & $(35)$ & (12) & $(63)$ & (63) & (34) \\
\hline Nada & 6.0 & 63.0 & - & 19.0 & 89.0 & - \\
\hline Algo & 17.0 & 26.0 & 25.0 & 13.0 & 9.5 & 26.5 \\
\hline Parte & 20.0 & 11.0 & 16.5 & 16.0 & 1.5 & 29.5 \\
\hline Mayor parte & 23.0 & - & 42.0 & 8.0 & - & 9.0 \\
\hline Todo & 34.0 & - & 16.5 & 44.0 & - & 35.0 \\
\hline Limpiar la casa & $(35)$ & (35) & (18) & $(63)$ & $(63)$ & (39) \\
\hline Nada & 20.0 & 97.0 & - & 27.0 & 100.0 & - \\
\hline Algo & 20.0 & - & 5.5 & 9.5 & - & 10.0 \\
\hline Parte & 23.0 & 3.0 & 33.2 & 19.0 & - & 31.0 \\
\hline Mayor parte & 11.0 & - & 28.0 & 6.5 & - & 15.0 \\
\hline Todo & 26.0 & - & 33.2 & 38.0 & - & 44.0 \\
\hline Lavar la ropa & $(35)$ & (35) & (13) & $(63)$ & (63) & (24) \\
\hline Nada & 20.0 & 89.0 & - & 22.0 & 97.0 & - \\
\hline Algo & 3.0 & 5.5 & 8.0 & - & - & 4.0 \\
\hline Parte & 14.0 & 5.5 & 38.0 & 17.5 & 1.5 & 42.0 \\
\hline Mayor parte & 9.0 & - & 8.0 & 1.6 & - & - \\
\hline Todo & 54.0 & - & 46.0 & 59.0 & 1.5 & 54.0 \\
\hline Planchar & $(35)$ & $(35)$ & $(23)$ & (63) & $(63)$ & (38) \\
\hline Nada & 40.0 & 97.0 & - & 38.0 & 100.0 & - \\
\hline Algo & 11.0 & 3.0 & 13.3 & 3.0 & - & 10.0 \\
\hline Parte & 9.0 & - & 13.3 & 13.0 & - & 21.0 \\
\hline Mayor parte & 6.0 & - & 13.3 & 6.0 & - & 6.0 \\
\hline Todo & 34.0 & - & 60.0 & 40.0 & - & 63.0 \\
\hline Hacer las compras & (35) & $(35)$ & $(5)$ & $(63)$ & (63) & (11) \\
\hline Nada & 3.0 & 34.0 & - & 8.0 & 76.2 & - \\
\hline Algo & 11.5 & 11.0 & 80.0 & 1.5 & 3.2 & 64.0 \\
\hline Parte & 48.5 & 46.0 & 20.0 & 19.0 & 16.0 & 18.0 \\
\hline Mayor parte & 8.5 & 6.0 & - & 8.0 & 1.5 & - \\
\hline Todo & 28.5 & 3.0 & - & 63.5 & 3.1 & 18.0 \\
\hline
\end{tabular}


CUADRO 1 (continuación)

\begin{tabular}{|c|c|c|c|c|c|c|}
\hline \multirow{2}{*}{$\begin{array}{l}\text { Participación } \\
\text { en actividades }\end{array}$} & \multicolumn{3}{|c|}{ Hogar actual } & \multicolumn{3}{|c|}{ Hogar de origen } \\
\hline & Ellas & Ellos & Otros & $\overline{\text { Ellas }}$ & Ellos & Otros \\
\hline Pagar las cuentas & (35) & (35) & - & $(60)$ & $(60)$ & (2) \\
\hline Nada & 31.5 & 34.0 & - & 50.0 & 37.0 & - \\
\hline Algo & 8.5 & 3.0 & - & 3.0 & 1.5 & 50 \\
\hline Parte & 23.0 & 23.0 & - & 12.0 & 12.0 & - \\
\hline Mayor parte & 3.0 & 8.5 & - & - & 1.5 & - \\
\hline Todo & 34.0 & 31.5 & - & 35.0 & 48.0 & 50 \\
\hline Cuidar el auto & (29) & (29) & (1) & $(51)$ & (51) & (4) \\
\hline Nada & 76.0 & 3.5 & - & 90.0 & 10.0 & - \\
\hline Algo & 10.0 & 3.5 & - & 2.0 & $\dot{-}$ & 25.0 \\
\hline Parte & 7.0 & 10.0 & 100.0 & 4.0 & 4.0 & - \\
\hline Mayor parte & 3.5 & 10.0 & - & - & 4.0 & - \\
\hline Todo & 3.5 & 73.0 & - & 4.0 & 82.0 & 75.0 \\
\hline $\begin{array}{l}\text { Arreglos menores de } \\
\text { grifería y plomería }\end{array}$ & (35) & (35) & (8) & (61) & $(61)$ & (23) \\
\hline Nada & 80.0 & 17.0 & - & 92.0 & 34.5 & - \\
\hline Algo & 6.0 & 6.0 & - & 1.5 & 3.5 & 4.0 \\
\hline Parte & 11.0 & 14.0 & 25.0 & - & 3.5 & 17.5 \\
\hline Mayor parte & - & 3.0 & 12.5 & - & 1.5 & 17.5 \\
\hline Todo & 3.0 & 60.0 & 62.5 & 6.5 & 57.0 & 61.0 \\
\hline
\end{tabular}

CUADRO 2

Participación en actividades de cuidado de los hijos en el hogar actual, versión de ellas, y en el hogar de origen (porcentajes)

\begin{tabular}{lccccccc}
\hline \multirow{2}{*}{$\begin{array}{l}\text { Participación } \\
\text { en actividades }\end{array}$} & \multicolumn{3}{c}{ Hogar actual } & & \multicolumn{3}{c}{ Hogar de origen } \\
\cline { 2 - 4 } \cline { 5 - 6 } Ellas & \multicolumn{2}{c}{ Ellos } & Otros & & Ellas & Ellos & Otros \\
\hline Bañarlos & $(28)$ & $(28)$ & $(2)$ & $(18)$ & $(18)$ & $(6)$ \\
$\quad$ Nada & - & 36.0 & - & 5.0 & 89.0 & - \\
Algo & 3.5 & 39.5 & 50.0 & 5.0 & 11.0 & 33.5 \\
Parte & 25.0 & 21.0 & 50.0 & 17.0 & - & 50.0 \\
Mayor parte & 39.5 & 3.5 & - & 5.0 & - & 16.5 \\
Todo & 32.0 & - & - & 67.0 & - & - \\
Vestirlos & $(28)$ & $(28)$ & $(2)$ & $(18)$ & $(18)$ & $(5)$ \\
Nada & - & 36.0 & - & 5.0 & 94.0 & - \\
Algo. & - & 36.0 & - & - & 6.0 & 20.0 \\
Parte & 36.0 & 28.0 & 100.0 & 17.0 & - & 60.0 \\
Mayor parte & 36.0 & - & - & 11.0 & - & - \\
Todo & 28.0 & - & - & 67.0 & - & 20.0
\end{tabular}


CUADRO 2 (continuación)

\begin{tabular}{|c|c|c|c|c|c|c|}
\hline \multirow{2}{*}{$\begin{array}{l}\text { Participación } \\
\text { en actividades }\end{array}$} & \multicolumn{3}{|c|}{ Hogar actual } & \multicolumn{3}{|c|}{ Hogar de origen } \\
\hline & Ellas & Ellos & Otros & Ellas & Ellos & Otros \\
\hline Hacerlos dormir & $(28)$ & (28) & (1) & (13) & (13) & (2) \\
\hline Nada & 11.0 & 14.0 & - & 7.5 & 54.0 & - \\
\hline Algo & 14.0 & 3.0 & 100.0 & 7.5 & 7.5 & 100.0 \\
\hline Parte & 61.0 & 61.0 & - & 31.0 & 31.0 & - \\
\hline Mayor parte & - & 11.0 & - & 7.5 & - & - \\
\hline Todo & 14.0 & 11.0 & - & 46.5 & 7.5 & - \\
\hline Llevarlos a la escuela & $(29)$ & (29) & (7) & (53) & (53) & (13) \\
\hline Nada & 39.0 & 45.0 & - & 38.0 & 62.0 & - \\
\hline Algo & 3.0 & 7.0 & - & - & 6.0 & - \\
\hline Parte & 31.0 & 24.0 & 28.5 & 13.0 & 15.0 & 38.5 \\
\hline Mayor parte & 7.0 & - & 14.5 & 6.0 & - & - \\
\hline Todo & 20.0 & 24.0 & 57.0 & 43.0 & 17.0 & 61.5 \\
\hline \multicolumn{2}{|c|}{ Ayudarlos con deberes (19) } & (19) & (1) & (55) & (55) & (5) \\
\hline Nada & - & 42.0 & - & 11.0 & 56.5 & - \\
\hline Algo & 10.5 & 21.0 & 100.0 & 3.5 & 9.0 & 40.0 \\
\hline Parte & 31.5 & 32.0 & - & 29.0 & 27.0 & - \\
\hline Mayor parte & 16.0 & 5.0 & - & 5.5 & 2.0 & - \\
\hline Todo & 42.0 & - & - & 51.0 & 5.5 & 60.0 \\
\hline \multicolumn{2}{|c|}{ Hablar con la maestra (27) } & (27) & - & (61) & (61) & \\
\hline Nada & 4.0 & 44.0 & - & 1.0 & 84.0 & - \\
\hline Algo & 4.0 & 15.0 & - & - & 5.0 & - \\
\hline Parte & 33.0 & 33.0 & - & 10.0 & 10.0 & - \\
\hline Mayor parte & 15.0 & 4.0 & - & 5.0 & - & - \\
\hline Todo & 44.0 & 4.0 & - & 84.0 & 1.0 & - \\
\hline Reprenderlos & (33) & (33) & - & $(63)$ & (63) & (1) \\
\hline Nada & - & 3.0 & - & 8.0 & 29.0 & - \\
\hline Algo & 3.0 & 9.0 & - & 3.0 & 11.0 & 100.0 \\
\hline Parte & 85.0 & 85.0 & - & 51.0 & 51.0 & - \\
\hline Mayor parte & 9.0 & 3.0 & - & 9.0 & 1.0 & - \\
\hline Todo & 3.0 & - & - & 29.0 & 8.0 & - \\
\hline Llevarlos al médico & (35) & (35) & - & (62) & (62) & - \\
\hline Nada & 6.0 & 40.0 & - & 1.5 & 77.5 & $\therefore$ \\
\hline Algo & - & 11.0 & - & - & 1.5 & - \\
\hline Parte & 43.0 & 43.0 & - & 19.5 & 19.5 & - \\
\hline Mayor parte & 11.0 & - & - & 1.5 & - & - \\
\hline Todo & 40.0 & 6.0 & - & 77.5 & 1.5 & - \\
\hline Comprarles ropa & (35) & (35) & (4) & (63) & (63) & - \\
\hline Nada & 6.0 & 63.0 & - & 1.5 & 84.0 & - \\
\hline Algo & 6.0 & 14.0 & 25.0 & 1.5 & 1.5 & - \\
\hline Parte & 23.0 & 23.0 & - & 11.0 & 11.0 & - \\
\hline Mayor parte & 11.0 & - & 25.0 & 1.5 & 1.5 & - \\
\hline Todo & 54.0 & - & 50.0 & 84.0 & 1.5 & - \\
\hline
\end{tabular}




\section{Bibliografía}

Anker, R. (1997a), "La segregación profesional entre hombres y mujeres. Repaso de las teorías", Revista Internacional del Trabajo, vol. 116, núm. 3.

- $(1997 \mathrm{~b})$, "La segregación profesional entre hombres y mujeres. Investigación empírica sobre los países nórdicos", Revista Internacional del Trabajo, vol. 3, núm. 3 .

Arriagada, I. (1990), "La participación desigual de la mujer en el mundo del trabajo", Revista de la CEPAL, núm. 40.

Bernard, J. (1981), "The Good Provider Role: Its Rise and Fall", American Psychologist, vol. 36, núm. 1.

Berk, S. F. (1985), The Gender Factory, Nueva York, Plenum.

Dunn, D. (1997), Workplace/Women's Place, California, Roxbury Publishing.

Durán, M. A. (1988), De puertas adentro, Madrid, Instituto de la Mujer.

Fassinger, P. A. (1993), "Meanings of Housework for Single Fathers and Mothers: Insights into Gender Inequality", en J. C. Hood, Men, Work and Family, Newbury Park, Sage.

García, B. y O. de Oliveira (1994), Trabajo femenino y vida familiar en México, México, El Colegio de México.

Giddens, A. (1992), Las transformaciones de la intimidad. Sexualidad, amor y erotismo en las sociedades modernas, Madrid, Cátedra.

Goldscheider, F. K. y L. Waite (1991), New Families, No Families, Berkeley, University of California (Studies in Demography, 6).

Greenstein, T. N. (1996), "The Husband's Participation in Domestic Labor: Interactive Effects of Wives' and Husbands' Gender Ideologies", Journal of Marriage and the Family, vol. 58.

Hass, L. (1993), "Nurturing Fathers and Working Mothers. Changing Gender Roles in Sweden", en J. C. Hood, Men, Work and Family, Newbury Park, Sage.

Hertrich, V. (1997), "Les réponses des hommes valent-elles celles de femmes?”, Population, vol. 52, núm. 1.

Hochschild, A. R. (1989), The Second Shift, Nueva York, Avon Books.

Hood, J. (1985), "The Provider Role: Its Meaning and Measurement", Journal of Marriage and the Family, vol. 48. (1993), Men, Work, and Family, Newbury Park, Sage.

Morris, L. (1990), The Workings of the Household, Cambridge, Polity Press.

Pantelides, E. A., R. N. Geldstein y G. Infesta (1995), Imágenes de género y conducta reproductiva en la adolescencia, Buenos Aires, Cenep (Cuadernos del Cenep, 51).

Pleck, J. H. (1976-1977), "The Work-Family Role System", Social Problems, vol. 24.

(1987), "American Fathering in Historical Perspective", en M. S. Kimmel (ed.), Changing Men: New Directions in Research on Men and Masculinity, Newbury Park, Sage. 
Presser, H. (1995), "Are the Interests of Women Inherently at Odds with the Interests of Children or the Family? A Viewpoint", en K. Oppenheim Mason, y A. M. Jensen (eds.), Gender and Family in Industrialized Countries, Nueva York, Oxford University Press.

Ramos Torres, R. (1990), Cronos divididos. Uso del tiempo y desigualdad entre mujeres y hombres en España, Madrid, Instituto de la Mujer.

Shelton, B. A. y D. John (1996), "The Division of Household Labor", Annual Review of Sociology, vol. 22.

Szinovacz, M. (1984), "Changing Family Roles and Interactions", Marriage and Family Review, num. 7.

Wainerman, C. H. (1979), "Educación, familia y participación económica en la Argentina", Desarrollo Económico, vol. 18, núm. 72.

- y R. N. Geldstein (1994), "Viviendo en familia: ayer y hoy", en C. H. Wainerman (ed.), Vivir en Familia, Buenos Aires, UNICEF/Losada.

Warshofsky Lapidus, G. (1988), "The Interaction of Women's Roles in the URSS", Women and Work, vol. 3.

Zhang, Ch. y J. Farley (1995), "Gender and the Distribution of Household Work: A Comparison of Self-Reports by Female College Faculty in the United States and China", Joumal of Comparative Studies, vol. 26, núm. 2. 